\title{
Teaching and learning in a Xenopus research lab
}

\author{
Shan Yan, PhD, Assistant Professor, Department of Biological Sciences, \\ University of North Carolina, Charlotte, NC
}

Dr. Yan shares his growth and accomplishments as a researcher and teacher, working with Xenopus egg extracts to explore genomic instability and tumorigenesis.

You have been working with animal models since your PhD research at Fudan University in Shanghai. What inspired you to pursue a career in research with lab animals?

I was a sophomore at Shandong University when 'Dolly' the sheep was cloned by nuclear transfer from an adult somatic cell. I was inspired by this news and began studying literature on fertilization and development, where I found the seminal work of pioneering experimental biologist Dr. Tschou Su. Dr. Tschou's research was fascinating to me because it demonstrated that unfertilized toad oocytes could be punctured by a needle and still develop into normal adults. I later accepted an offer to pursue my $\mathrm{PhD}$ at Fudan University under Professor Jiake Tso, who inherited the lab and research of Dr. Tschou, where I began studying oocyte maturation in toads.

You currently research genomic instability and teach biology as an assistant professor at UNC Charlotte. How have you developed and balanced your research interests with your teaching responsibilities?

My process of becoming an independent scholar benefitted from the guidance of strong mentors, who taught me how to be independent and find my own path. This approach does not eschew collaboration with other scientists but rather encourages critical thinking within my own research.

My career goal now is to be a successful teacher and scholar. I have trained in classroom instruction at Harvard University and I attended several workshops and seminars for teaching in the greater Boston area. I was fortunate to work as a teaching assistant at Harvard, which better prepared me to teach biology. Here, at UNC Charlotte, the Center for Teaching and Learning offers teaching workshops and learning resources, and the National Science Foundationfunded ADVANCE program provides resources for mentoring and new faculty transitions. Finally, my colleagues here have helped me refine my research and teaching, through comments on grant proposals, classroom observations and peer evaluation.

\section{Your current research program at UNC Charlotte involves postdoctoral fellows and graduate, undergraduate and high school students. What kinds of learning opportunities does your research offer?}

As a faculty member of UNC Charlotte, I am committed to mentoring students and fellows at many different levels. Students in my lab are often supported by various scholar programs, and graduate students have opportunities to teach lab sessions as teaching assistants and to deliver presentations at conferences. I hold a monthly discussion series in my lab that covers topics of career development, such as "How to be a Professional Scientist," "Grant Proposal Writing 101" and "Presentation Skills." I have also implemented a 'peer learning' model in my lab, wherein postdoctoral fellows advise graduate students, who, in turn, supervise undergraduate students. In this way students and fellows practice teaching and learning outside the classroom. I usually hold weekly group meetings to assess and discuss peer learning, progress on lab projects and any problems that

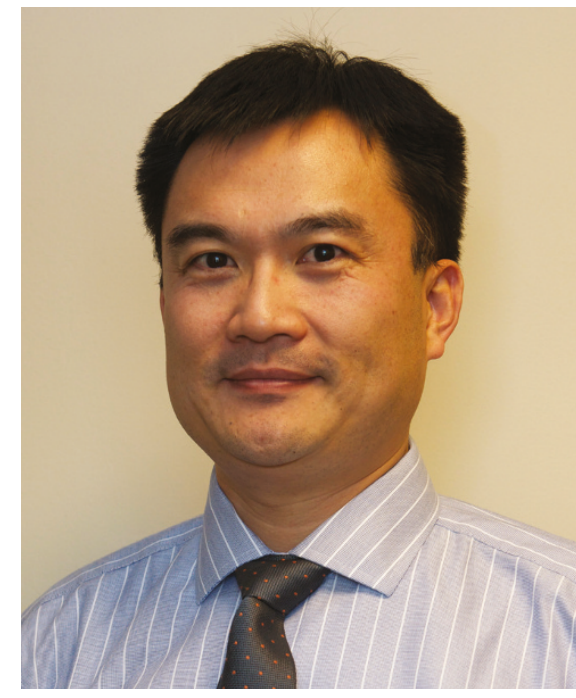

we encounter. As a testament to my lab's integration of teaching and research, I am proud to share that an undergraduate honors student shared first authorship with a graduate student on a recent manuscript published in Proceedings of the National Academy of Sciences.

\section{You helped establish a new Xenopus facility within the UNC Charlotte vivarium. Tell us about its challenges and rewards.}

Our new facility houses approximately 200 frogs on three stand-alone rack systems within the vivarium, and it is a challenge to keep the frogs healthy. Luckily we have excellent support at the vivarium, including staff technicians and the director, our attending veterinarian. After my Xenopus protocol was approved, I became a standing member of the IACUC and I now participate in many of its functions, including protocol review and facility monitoring.

Our Xenopus facility has generally created opportunities to share our research with the broader scientific community. My students have produced a resource for the Journal of Visualized Experiments, describing in video and in writing how we use Xenopus egg extracts to study pathways of DNA damage response. We also share our research through tours of the lab as part of the North Carolina Science Festival. 